\title{
Padrão do uso de álcool por usuários de uma Unidade de Saúde da Família ${ }^{1}$
}

\author{
Renata Gomes Sanches Verardino ${ }^{a}$, Sonia Regina Zerbetto ${ }^{b}$ \\ aUniversidade Federal de São Carlos - UFSCar, São Carlos, SP, Brasil

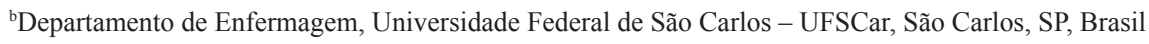

\begin{abstract}
Resumo: Introdução: No contexto das drogas, o álcool é um dos maiores problemas de saúde pública. Objetivo: identificar o padrão de consumo de bebida alcoólica dos usuários de uma Unidade de Saúde da Família do interior paulista, durante o acolhimento. Métodos: Estudo exploratório, transversal, de método quantitativo, com a utilização do Alcohol Use Disorders Identification Test (AUDIT) em 100 usuários adultos do serviço da rede de Atenção Primária à Saúde. Realizou-se análise estatística descritiva. Resultados: Da amostra, 74\% são mulheres, $85 \%$ fazem uso de bebida alcoólica em baixo risco, $19 \%$ são adultos jovens, o beber em excesso foi relatado pela minoria dos entrevistados. Da amostra, $42 \%$ dos católicos nunca fizeram uso de álcool em binge, seguidos pelos evangélicos, com 22\%. Conclusões: Os profissionais de saúde precisam ter conhecimento sobre o padrão de consumo de álcool dos moradores do território de abrangência da sua unidade, para que possam desenvolver ações de prevenção e promoção da saúde.
\end{abstract}

Palavras-chave: Etanol, Alcoolismo, Programa Saúde da Família, Atenção Primária à Saúde.

\section{Pattern of alcohol use by users of a family health unit}

\begin{abstract}
Background: Within the context of drugs, alcoholism is one of the major problems in public health. Objective: To identify the pattern of consumption of alcoholic beverages by users of a Family Health Unit in São Paulo state during reception. Method: Exploratory cross-sectional study of quantitative methodology with the use of Alcohol Use Disorder Identification Test (AUDIT) in 100 adult users of a Primary Health Care network. Descriptive statistical analysis was carried out. Results: Of the total sample, (74\%) were women, (85\%) made use of alcoholic beverages at low risk, and (19\%) were young adults; binge drinking was reported by a minority of the interviewees. The Catholics in the sample (42\%) reported never using alcohol excessively, followed by the Evangelicals with $22 \%$. Conclusions: Health professionals need to have knowledge of the alcohol consumption pattern of the residents from the territory of their unit, so that they can develop prevention and health promotion programs.
\end{abstract}

Keywords: Ethanol, Alcoholism, Family Health Program, Primary Health Care.

\section{Introdução}

O consumo de álcool é considerado um dos maiores problemas de saúde pública, tanto internacionalmente como no Brasil. O II Levantamento Domiciliar Nacional sobre o uso de drogas psicotrópicas, realizado em 2005, registrou uma taxa de $(12,3 \%)$ de dependentes de álcool na população geral brasileira, além do que 74,6\% dos entrevistados fizeram algum uso de álcool na vida, sendo 49,8\% de uso ao ano e 38,3\% uso ao mês de bebidas alcoólicas (CARLINI et al., 2006).

A prevalência da dependência de álcool foi de $17,1 \%$ para o sexo masculino e $5,7 \%$ para o feminino em uma amostra populacional brasileira de 8.589 entrevistados. No Brasil, 5,2\% dos adolescentes (12 a 17 anos de idade) são dependentes do álcool. A cerveja está entre as bebidas mais consumidas pelos 
estudantes do $1^{\circ}$ e $2^{\circ}$ graus, por cerca de $70 \%$ dos estudantes. O uso pesado de álcool foi maior nas classes sociais mais elevadas. A literatura ainda aponta que a bebida alcoólica foi responsável por cerca de $90 \%$ de todas as internaçóes hospitalares por dependência (GALDURÓZ; CAETANO, 2004).

Estudo sobre padrōes de uso de álcool entre usuários que frequentaram serviços de atenção primária à saúde de duas cidades mineiras, com a utilização do Alcohol Use Disorders Identification Test (AUDIT), apontou que a maior parte dos usuários entrevistados fez uso de baixo risco ou eram abstêmios (77,9\%); 18,3\% consumiram álcool no modo de risco ou abusivo e $3,8 \%$ sugeriram dependência. Outro dado demonstrou que os homens $(30,9 \%)$ estão em padrão de consumo de risco nocivo com maior frequência que as mulheres $(12,7 \%)$ (RONZANI; FORMIGONI; MAGNABOSCO, 2007). Os dados nacionais de prevalência de dependentes em relação ao sexo apontam que a dependência é maior para o sexo masculino (19,5\%) do que para feminino (6,9\%) (CARLINI et al., 2006; VARGAS; OLIVEIRA; ARAÚJO, 2008).

Uma pesquisa ressaltou que $22,2 \%$ dos usuários de serviços de Atençáo Primária à Saúde de duas cidades do interior de Minas Gerais fizeram uso abusivo de álcool, o que preocupou as autoridades de saúde, podendo ele estar relacionado a uma ingestão em elevadas quantidades em uma única ocasião (binge drinking), possibilitando que a sua alta frequência gere vários problemas de saúde, bem como danos sociais, físicos, psicológicos, trabalhistas, financeiros e legais (RONZANI; FORMIGONI; MAGNABOSCO, 2007).

Um estudo realizado no interior do estado de São Paulo apontou que homens fumantes, com maior escolaridade e com diagnóstico de gastrite e diabetes estão em um grupo com maior risco para a dependência alcoólica e que também são os que apresentam mais morbidade e mortalidade relacionadas com o uso de substância alcoólica. A pesquisa ainda mostrou que $9,8 \%$ dos homens que procuraram atendimento na Unidade de Saúde da Família (USF) eram dependentes do álcool e apresentavam doenças devido ao consumo abusivo do álcool, o que evidencia a importância de se fazer a detecção de casos nesse nível de atenção (VARGAS; OLIVEIRA; ARAÚJO, 2008).

Dessa maneira, a caracterização dos padróes de uso de álcool de usuários atendidos durante o acolhimento de uma USF permite uma visão dessa clientela e a elaboraçáo de estratégias de prevenção e controle do consumo. $\mathrm{O}$ acolhimento nesse estudo é entendido como uma etapa do processo do trabalho, responsável pelo atendimento da demanda, ou seja, um instrumento para reorganizar o serviço em saúde.

Este estudo justifica-se na medida em que a maioria das pessoas que faz uso problemático de álcool não é diagnosticada até surgirem sérias complicaçóes advindas da bebida alcoólica. Espera-se que esta pesquisa possa contribuir na identificação de usuários com problemas relacionados ao consumo de álcool. Além disso, busca-se auxiliar o profissional da saúde a realizar uma melhor intervenção e, ao usuário do serviço, dar um retorno sobre o seu padrão de consumo dessa bebida. Com o estudo espera-se contribuir na produção de conhecimento relacionado ao problema do álcool, reforçando a importância do AUDIT enquanto instrumento que pode ser implementado no cotidiano do trabalho do profissional da rede básica de saúde. Assim, esta pesquisa tem como objetivo geral caracterizar uma amostra de usuários adultos quanto ao padrão de consumo de álcool, durante o processo de acolhimento de uma USF de uma cidade do interior do estado de São Paulo, utilizando-se do instrumento de rastreamento AUDIT. Como objetivos específicos, propôe-se identificar o padrão de consumo de álcool de uma amostra desses usuários do serviço de saúde, bem como classificar os indivíduos que fazem uso de álcool, conforme as zonas de risco do citado instrumento de rastreamento.

\section{Método}

Trata-se de um estudo exploratório, transversal, descritivo e de método quantitativo, pois objetivou-se a busca de informações a respeito de sujeitos a fim de caracterizá-los evidenciando um perfil (BREVIDELLI; DOMENICO, 2006). O trabalho de campo foi realizado em uma USF de uma cidade do interior do estado de São Paulo, entre os meses de novembro de 2011 a março de 2012.

Foram os sujeitos uma amostragem não probabilística de 100 usuários adultos $(\mathrm{n}=100)$, considerando a média de acolhimento mensal na USF, com idade maior ou igual a 18 anos, alfabetizados ou não, sem comprometimento cognitivo aparente, sem quadro de intoxicação alcoólica, recrutados por conveniência durante o processo de acolhimento na unidade. O critério de exclusão consistiu nos sujeitos menores de 18 anos, adultos com aparente comprometimento cognitivo e em estado de embriaguez.

Utilizou-se um questionário constituído por informações pessoais (sexo, idade, religião) e o instrumento denominado Questionário de 
Identificação de Transtornos pelo Consumo de Álcool (AUDIT). O AUDIT é um instrumento de rastreamento desenvolvido pela Organização Mundial da Saúde validado no Brasil composto por 10 questôes com enfoque no padrão de consumo do usuário (quantidade e frequência), possível sintomatologia de dependência e problemas recentes e passados associados ao consumo. As respostas a cada questão são pontuadas de $1 \mathrm{a} 4$, sendo as maiores pontuaçôes indicativas de problemas. Os escores do instrumento possibilitam identificar as zonas de risco, tais como zona I (até 7 pontos - consumo de baixo risco ou abstemia), zona II (de 8 a 15 pontos - indica uso de risco), zona III (de 16 a 19 pontos - uso nocivo) e zona IV (de 20 a 40 pontos - sugere dependência) (BABOR et al., 2001; LARANJEIRA et al., 2007).

Considera-se uso de risco de álcool quando o indivíduo ainda não teve dano físico, mental, social, legal ou econômico mas está correndo sérios riscos de sofrer essas consequências graves devido a seu modo de beber excessivamente. $\mathrm{O}$ uso abusivo ou nocivo é compreendido quando o indivíduo apresenta danos biológicos, psíquicos, legais, financeiros, sociais, no âmbito do trabalho ou doméstico. A Síndrome de Dependência Alcoólica é diagnosticada quando a pessoa apresenta três ou mais dos sintomas: forte desejo ou sentimento compulsivo para beber; dificuldade de controlar o consumo; estado de abstinência fisiológica quando cessa de beber; evidência de tolerância, ou seja, necessidade de doses maiores para obter o mesmo efeito anterior; abandono progressivo de atividades não relacionadas com o beber; persistir no consumo apesar de já ter apresentado danos com o modo de beber (BABOR et al., 2001).

O AUDIT foi aplicado durante o atendimento dos sujeitos, na etapa do acolhimento, em horários e salas previstos pela instituição e que melhor convieram ao usuário. No processo de abordagem do usuário e início da entrevista foi utilizada a seguinte frase: "O uso de álcool pode afetar sua saúde e interferir com algumas medicaçóes e tratamentos. Assim, é importante a sua participação e, se possível, que você responda sobre o seu consumo de álcool ao longo dos últimos 12 meses".

Os sujeitos foram orientados quanto ao significado de dose padrão, conforme imagens dos recipientes de cada tipo de bebida inseridas no próprio instrumento de rastreamento. No Brasil, uma dose padrão de álcool contém 12 gramas de etanol puro. Em relação aos tipos de bebida, uma dose padrão corresponde a uma lata de cerveja de 350 mililitros (ml), $140 \mathrm{ml}$ de vinho, $40 \mathrm{ml}$ de destilados (conhaque, pinga, uísque) e $40 \mathrm{ml}$ de aperitivo (licor) (BABOR et al., 2001).
Os participantes obtiveram retorno dos resultados do AUDIT logo após a sua aplicação. De acordo com o resultado do AUDIT, as açóes realizadas com os usuários foram no âmbito preventivo, envolvendo a disponibilização de informaçóes sobre os danos causados pelo uso excessivo de álcool, esclarecendo dúvidas e falsas crenças sobre tal substância, orientando sobre a necessidade de diminuir o consumo ou abster-se do beber, com encaminhamento para avaliaçáo de profissional de saúde.

Realizou-se análise estatística descritiva, com apoio do Programa Microsoft Office Excel versão 97-2003. Foram utilizados gráficos e tabelas de frequência simples para análise individual das variáveis idade, sexo, religiấo, padrôes de uso de álcool e zonas de risco e tabelas bidimensionais para análise de duas variáveis simultaneamente (BUSSAB; MORETTIM, 2004).

Esta pesquisa foi aprovada pelo Comitê de Ética em Pesquisa da Universidade Federal de São Carlos - UFSCar, conforme o parecer n. 286/2011.

\section{Resultados}

A Tabela 1 apresenta a frequência e a percentagem da variável sexo. A partir de uma amostra de 100 indivíduos entrevistados, a população do sexo feminino foi de quase três vezes a do sexo masculino.

A Tabela 2 apontou a frequência e percentagem da variável zona de risco. Em relação à frequência e porcentagem de consumo de álcool nos últimos 12 meses constatou-se que a maioria $(85=85 \%)$ dos entrevistados foram classificados como em consumo de baixo risco.

Tabela 1. Frequência e porcentagem da variável sexo; São Carlos, SP, 2012.

\begin{tabular}{lccc}
\hline \multicolumn{1}{c}{ Sexo } & & f & \% \\
\hline Feminino & 74 & 0.74 & 74 \\
Masculino & 26 & 0.26 & 26 \\
Total & $\mathbf{1 0 0}$ & $\mathbf{1}$ & $\mathbf{1 0 0}$ \\
\hline
\end{tabular}

Tabela 2. Frequência e porcentagem da variável zona de risco; São Carlos, SP, 2012.

\begin{tabular}{lccc}
\hline $\begin{array}{l}\text { Pontuação zona de } \\
\text { risco }\end{array}$ & Entrevistados & f & \% \\
\hline $\begin{array}{l}\text { Consumo de baixo } \\
\text { risco }\end{array}$ & 85 & 0.85 & 85 \\
Uso risco & 7 & 0.07 & 7 \\
$\begin{array}{l}\text { Uso nocivo } \\
\begin{array}{l}\text { Provável } \\
\text { dependência }\end{array}\end{array}$ & 4 & 0.04 & 4 \\
Total & 4 & 0.04 & 4 \\
\hline
\end{tabular}


Dos 69 usuários que nunca fizeram uso de álcool em forma de binge, a Tabela 3 demonstrou que a maioria (57\%) é do sexo feminino e que $12 \%$ são do sexo masculino. Por sua vez, o número de homens que já bebeu em modo de binge no último ano ainda é discretamente maior que o número de homens que nunca bebeu abusivamente.

A Tabela 4 evidencia a relação da frequência de consumo de cinco ou mais doses em uma única ocasiāo em relação à faixa etária. Verificou-se um predomínio de indivíduos adultos jovens que fizeram uso em binge no último ano.

Pelo resultado da Tabela 5 identificou-se que $42 \%$ dos católicos nunca fizeram uso de álcool em binge, seguidos pelos evangélicos, com $22 \%$. No entanto, foi possível apreender que os evangélicos são os que menos fazem uso da bebida alcoólica em binge.

\section{Discussão}

Conforme resultado apontado na Tabela 1, a maioria da amostra estudada na USF foi composta por mulheres, demonstrando que usuários do sexo feminino buscaram mais atendimento nesse equipamento de saúde.

A organização do serviço na Estratégia Saúde da Família (ESF), cujo horário de funcionamento coincide com o período tradicional de trabalho, bem como o desconhecimento da importância do cuidado à saúde e fatores culturais são os determinantes para a escassa frequência dos homens nesses ambientes (SILVA et al., 2010).

Quanto ao padrão de consumo de álcool verificado na USF do município em estudo, de acordo com a zona de risco, observou-se que da amostra de 100 indivíduos a maioria (85\%) fez uso de baixo risco. Do total de $8 \%$ dos usuários, identificou-se que $4 \%$ fazem uso nocivo e que $4 \%$ foram classificados como prováveis dependentes. Tais dados corroboram estudo envolvendo 371 usuários da Atenção Básica de Saúde de Juiz de Fora, MG, que apontou que 81,9\% deles classificaram-se na pontuação consumo de baixo risco. Em contrapartida, 18,1\% estavam em uso de

Tabela 3. Relação entre sexo e binge; São Carlos, SP, 2012.

\begin{tabular}{lccccccc}
\hline \multirow{2}{*}{ Sexo } & \multicolumn{3}{c}{ Binge (frequência de consumo de cinco ou mais doses em uma única ocasião } & \\
\cline { 2 - 7 } & Nunca (0) & $\begin{array}{c}\text { Menos que uma } \\
\text { vez por mês (1) }\end{array}$ & $\begin{array}{c}\text { Uma vez por } \\
\text { mês (2) }\end{array}$ & $\begin{array}{c}\text { Uma vez por } \\
\text { semana (3) }\end{array}$ & $\begin{array}{c}\text { Quase todos os } \\
\text { dias (4) }\end{array}$ & Total \\
\hline Feminino & 57 & 9 & 5 & 3 & 0 & 74 \\
Masculino & 12 & 3 & 6 & 4 & 1 & 26 \\
Total & $\mathbf{6 9}$ & $\mathbf{1 2}$ & $\mathbf{1 1}$ & $\mathbf{7}$ & $\mathbf{1}$ & $\mathbf{1 0 0}$ \\
\hline
\end{tabular}

Tabela 4. Relação entre idade e binge; São Carlos, SP, 2012.

\begin{tabular}{cccccccc}
\hline \multirow{2}{*}{ Idade } & \multicolumn{6}{c}{ Binge (frequência de consumo de cinco ou mais doses em uma única ocasião) } & \\
\cline { 2 - 6 } & Nunca (0) & $\begin{array}{c}\text { Menos que uma } \\
\text { vez por mês (1) }\end{array}$ & $\begin{array}{c}\text { Uma vez por } \\
\text { mês (2) }\end{array}$ & $\begin{array}{c}\text { Uma vez por } \\
\text { semana (3) }\end{array}$ & $\begin{array}{c}\text { Quase todos os } \\
\text { dias (4) }\end{array}$ & Total \\
\hline $18-26$ & 13 & 3 & 3 & 1 & 0 & $\mathbf{2 0}$ \\
$27-34$ & 10 & 3 & 2 & 3 & 1 & $\mathbf{1 9}$ \\
$35-42$ & 7 & 2 & 5 & 0 & 0 & $\mathbf{1 4}$ \\
$43-50$ & 9 & 0 & 0 & 1 & 0 & $\mathbf{1 0}$ \\
$51-58$ & 13 & 2 & 0 & 2 & 0 & $\mathbf{1 7}$ \\
$59-66$ & 6 & 2 & 1 & 0 & 0 & $\mathbf{9}$ \\
$67-74$ & 7 & 0 & 0 & 0 & 0 & $\mathbf{7}$ \\
$75-82$ & 4 & 0 & 0 & 0 & 0 & $\mathbf{4}$ \\
Total & $\mathbf{6 9}$ & $\mathbf{1 2}$ & $\mathbf{1 1}$ & $\mathbf{7}$ & $\mathbf{1}$ & $\mathbf{1 0 0}$ \\
\hline
\end{tabular}

\begin{tabular}{lccccccc}
\hline \multirow{2}{*}{ Religião } & \multicolumn{6}{c}{ Religião e binge } & \\
\cline { 2 - 6 } & Nunca (0) & $\begin{array}{c}\text { Menos que uma } \\
\text { vez por mês (1) }\end{array}$ & $\begin{array}{c}\text { Uma vez por } \\
\text { mês (2) }\end{array}$ & $\begin{array}{c}\text { Uma vez por } \\
\text { semana (3) }\end{array}$ & $\begin{array}{c}\text { Quase todos os } \\
\text { dias (4) }\end{array}$ & Total \\
\hline Católica & 42 & 7 & 9 & 7 & 1 & 66 \\
Evangélica & 22 & 2 & 0 & 0 & 0 & 24 \\
Espírita & 0 & 1 & 0 & 0 & 0 & 1 \\
Sem religião & 5 & 2 & 2 & 0 & 0 & 9 \\
Total & $\mathbf{6 9}$ & $\mathbf{1 2}$ & $\mathbf{1 1}$ & $\mathbf{7}$ & $\mathbf{1}$ & $\mathbf{1 0 0}$ \\
\hline
\end{tabular}


risco (AMATO et al., 2008). Os resultados citados acima vão ao encontro dos de estudo realizado por Laranjeira et al. (2010) no referente à frequência de consumo de álcool, segundo o qual metade da populaçấo adulta brasileira estava abstêmia durante os últimos 12 meses, com 3\% em situação abusiva e $9 \%$ em dependência.

De acordo com Amato et al. (2008), a maioria da populaçáo faz consumo de baixo risco e uma minoria de usuários bebe de forma abusiva ou prejudicial, sendo que tais informaçôes são importantes para que as equipes de saúde possam planejar açóes educativas para a problemática do álcool. Os dados demonstram a importância da utilização de instrumentos de rastreamento, os quais possibilitam aos trabalhadores de saúde identificar pessoas que consomem bebidas alcoólicas de modo problemático quando essas buscam atendimento nas unidades de saúde. As Estratégias de Diagnóstico e Intervenção Breve (EDIB), através da aplicação do AUDIT, auxiliam na detecçáo dos perigos do uso do álcool e permitem ações no âmbito preventivo, que envolvem educação para o álcool e aconselhamento simples. Porém ressalta-se que a confirmaçáa do diagnóstico de Síndrome de Dependência Alcoólica e abuso de álcool necessitará de avaliação médica e de outros parâmetros e recursos diagnósticos.

Em relação às variáveis sexo e binge, dados do I Levantamento Nacional sobre o Padrão de Consumo de Álcool mostraram que os homens são os que mais bebem no modo binge, totalizando $60 \%$ da população geral (LARANJEIRA et al., 2007). Entretanto, náo foi possível observar tal comportamento nesta pesquisa, visto que o número de homens entrevistados foi consideravelmente menor, o que pode decorrer do predomínio da populaçáo feminina na busca de atendimento na USF. Outra pesquisa evidenciou que os homens apresentam maior frequência nos padrôes de consumo do álcool, representando $83,5 \%$, e as mulheres, $68,3 \%$. A dependência entre os homens é de $19,5 \%$, enquanto que nas mulheres da mesma faixa etária é de $6,9 \%$, o que demonstra que as mulheres estão menos vulneráveis à dependência do que os homens (CARLINI et al., 2006). Porém, para alguns estudiosos, como Wolle e Zilbermam (2011), apesar de a mulher consumir menos álcool do que os homens, elas tendem a desenvolver abuso e dependência de maneira mais rápida, considerando os aspectos biológicos.

Apesar de os homens beberem mais, não se pode esquecer que o consumo de álcool por mulheres também é alto e preocupante. $\mathrm{O}$ sexo feminino está mais propenso a maiores consequências danosas advindas do álcool, considerando-se a baixa quantidade da enzima álcool-desidrogenase que metaboliza o álcool, menor quantidade de água corpórea, possibilitando alta concentração etílica sanguínea, bem como maior proporção de gordura no organismo, comparando-se tais componentes aos do sexo masculino, possibilitando maior sensibilidade aos efeitos tóxicos dessa bebida (BORDIN et al., 2010; WOLLE; ZILBERMAN, 2011).

A literatura salienta que as mulheres associam o uso do álcool a fatores ligados, sobretudo, à vida doméstica e sentimentos relacionados ao trabalho, como o não reconhecimento social de sua profissão, sobrecarga de trabalho, dupla jornada de trabalho, entre outros. Por sua vez, os homens associam o uso da bebida a fatores externos, como o trabalho (NOBREGA; OLIVEIRA, 2005; WOLLE; ZILBERMAN, 2011). Além disso, culturalmente, os latinos, mais especificamente os brasileiros, associam o ato de beber com festividades e atividades sociais diárias e de lazer, principalmente para o gênero masculino, em que há uma maior permissividade social ao consumo de álcool comparativamente às mulheres (LARANJEIRA et al., 2010).

Portanto, fica evidente que o uso de bebida alcoólica é influenciado também por questóes culturais e sociais, havendo uma normalização para o consumo de álcool pelo homem. Socialmente, o uso do álcool é caracterizado como algo necessário à constituição e afirmação da masculinidade (NOBREGA; OLIVEIRA, 2005; WOLLE; ZILBERMAN, 2011).

A literatura aponta ainda que brasileiros mais jovens bebem mais que a populaçáo com idade de 60 anos ou mais e essa diferença chega a ser de $89 \%$ quando comparados aos jovens de 18-24 anos. Outro dado relevante é que até os 44 anos de idade mais de $30 \%$ da população já consumiu cinco doses ou mais de álcool em uma única ocasião (LARANJEIRA et al., 2010).

Considerando tais evidências, é importante que o profissional de saúde tenha conhecimento do padrão de consumo de álcool dos usuários pertencentes à unidade de saúde e os compreenda no contexto que ele está inserido, possibilitando a ele trabalhar no âmbito da prevenção ao uso de álcool.

Dessa maneira, apreender e compreender os dados epidemiológicos é relevante, pois eles auxiliam os gestores no planejamento das políticas públicas e estratégias de prevenção que devem ter como foco os jovens, população mais atingida e influenciada pelo álcool. Sabe-se que a maior causa de problemas relacionados ao álcool na população geral é a intoxicação por essa substância psicoativa. Dessa 
forma, prevenir a intoxicação pelo álcool, bem como o consumo prejudicial dessa bebida é uma estratégia poderosa para evitar muitos dos seus danos.

Evidências científicas apontam que a utilização de instrumentos de rastreamento associados às Intervenções Breves ${ }^{2}$ tem eficácia e que qualquer profissional pode utilizá-los, desde que sejam preparados e que haja uma prévia capacitação, o que não tem ocorrido efetivamente nos equipamentos de saúde de base comunitária (MINTO et al., 2007).

A bebida alcoólica desencadeia sérios danos físicos e psíquicos para o adulto e para os adolescentes e jovens as consequências orgânicas são ainda mais sérias, considerando que é nessa fase que há formação e desenvolvimento das habilidades cognitivas (PEUKER; FOGAÇA; BIZARRO, 2006). Além disso, sabe-se que o uso abusivo do álcool pode ocasionar outros tipos de danos, tais como violência, acidentes, relaçóes sexuais de modo desprotegido, estando associado ainda a faltas e atrasos às aulas e ao dormir em sala de aula no dia seguinte após festas (PILLON; CORRADI-WEBSTER, 2006).

O beber problemático de álcool, principalmente no modo de binge, nem sempre é percebido pelos estudantes. A detecção do padrão de consumo pode ser útil para sensibilizá-los e motivá-los a reduzirem ou cessarem esse uso. A partir da identificação dos padrões de consumo de álcool há possibilidades de se elaborar estratégias de prevenção e controle desse beber para grupos específicos, nesse caso adolescentes e universitários (PILLON; CORRADI-WEBSTER, 2006).

Outro resultado importante apontado neste estudo relaciona-se à variável religião e o padrão de consumo de álcool. A religiosidade é compreendida como um sistema organizado de crenças, práticas, rituais e símbolos que possibilita aproximação transcendental entre o ser humano e Deus ou um poder superior (KOENIG, 2001; ABDALA et al., 2009).

Religiosidade e espiritualidade podem ser definidas como termos distintos, ou seja, constituindo-se a religião nas crenças a que um indivíduo adere, enquanto que espiritualidade é entendida como uma experiência atual do ser humano em relaçáo aos outros de sua espécie, com a natureza e Deus. Muitas vezes as pessoas utilizam-se de substâncias psicoativas em tentativas de lidarem com os desafios da vida, bem como para procurar algo que possa dar sentido à sua existência humana (ABDALA et al., 2009).

Os dados deste estudo corroboram a literatura, a qual ressalta que evangélicos bebem menos que católicos e pessoas sem religiáo. Tanto para o padrão binge quanto para o uso de risco, os não praticantes de religião apresentaram índice de duas a três vezes maior para tais formas de consumo de álcool (AMATO et al., 2008). Alguns autores apontaram que além de promoverem estilos de vida mais saudáveis, as crenças espirituais ajudam no tratamento das pessoas que fazem uso abusivo de álcool e outras drogas (GONÇALVES, 2008; ABDALA et al., 2009).

A religião pode ser considerada fator protetor para o consumo de álcool, como também auxiliar no processo de recuperação do indivíduo em dependência química e diminuir o número de recaídas. Além disso, a religiosidade pode facilitar a recuperação do dependente químico, possibilitando que ele sinta-se motivado e otimista diante do poder de sua fé, perceba seus suportes emocionais internos e externos, desenvolva habilidades de resiliência e enfrentamento da ansiedade, buscando minimizá-la (RIBEIRO, 2011).

As ideias do autor acima possibilitam inferir que uma das razóes de uma pessoa, que faz uso de álcool ou não, buscar ajuda na religião pode estar relacionada ao sentimento de angústia, impotência diante do sofrimento psíquico ou percepçáo de um "vazio na alma", ou seja, vazio existencial, e, portanto, a sua participação dos cultos religiosos pode proporcionar sensação de "aproximação" com uma entidade superior, minimizando a dor emocional e preenchendo o "vazio interior" com sentimentos de esperança. A pessoa que frequenta cultos religiosos semanalmente, por exemplo, pode ter garantida a abstemia e/ou as não recaídas? As normas e valores religiosos possibilitam ao indivíduo mudar sua atitude diária, portanto modificar o seu hábito de vida diária? Caso a religiāo preconize o não uso de substâncias psicoativas entre os seus fiéis, tal fato pode auxiliar no processo terapêutico do usuário e, portanto, também seria considerado como fator de proteção?

Segundo Dalgalarrondo et al. (2004), a pessoa, ao se filiar a uma crença religiosa, também se apropria de um conjunto de valores, comportamentos, símbolos e práticas sociais que envolvem o ato de aceitar ou recusar o uso de álcool. Para os autores, as normas e valores religiosos, quando introjetados nas pessoas, portanto, nas suas atitudes diárias, possibilitaram um menor uso de álcool; porém as práticas de participar e frequentar cultos religiosos não garantiram o não uso dessa substância psicoativa. A religiosidade incute valores morais com a finalidade de respeitar e preservar a vida do homem, promover estilo de vida e comportamentos saudáveis, além de gerar a crença na existência de um ser superior, que protege 
o homem, proporcionando-lhe um bem-estar, portanto, livre das drogas (ABDALA et al., 2009).

Historicamente, a religião sempre permeou o processo de cuidar das pessoas, sendo que na era do Cristianismo o cuidado aos pobres garantia ao cuidador um espaço garantido no céu, bem como a salvação de sua alma pecadora e a cura de seus males físicos e emocionais. Para Campana et al. (2008), nos povos primitivos e nas religiôes cristâs, o ser humano sempre buscou através da religião curar as doenças. Além disso, é através da religião que o indivíduo busca também explicações, justificativas para os problemas que o envolvem e significados para o seu sofrimento.

Salienta-se que os grupos de mútua ajuda, isto é, organizaçóes constituídas por pessoas que se unem em apoio mútuo diante do mesmo problema, trabalham com a espiritualidade no tratamento do uso de substância psicoativa. Esses grupos objetivam satisfazer uma necessidade comum entre eles e superar dificuldades que envolvem problemas físicos ou estilos de vida autodestrutivos, buscando a mudança social ou pessoal (MARINHO; SILVA; FERREIRA, 2011). Os grupos de mútua ajuda mais conhecidos são os Alcoólicos Anônimos (AA), Narcóticos Anônimos (N/A), Neuróticos Anônimos (NA) e Amor Exigente, esse último direcionado para familiares de dependentes químicos (ROEHE, 2004; MARINHO; SILVA; FERREIRA, 2011).

$\mathrm{O}$ que se percebe é que religião, religiosidade, espiritualidade constituem apoios para a recuperaçáo da pessoa que faz uso de substâncias psicoativas, e que elas atuam como fatores de proteção, porém ressalta-se que Comunidades Terapêuticas consideradas como serviços de atenção em regime residencial na maioria das vezes têm cunho religioso e não necessariamente são consideradas grupos adequados para o atendimento das pessoas que usam drogas. Esses serviços podem não possuir um profissional de saúde.

Porém, se a literatura registra que a religiáo pode ajudar algumas pessoas, também salienta que para outras ela é uma fonte de estresse que pode gerar grande sofrimento e reforçar o uso indevido de bebidas alcoólicas e outras drogas. Ainda há controvérsias científicas sobre a religião ser benéfica ou prejudicial, principalmente no âmbito do uso problemático de substâncias psicoativas, pois ela tanto pode reduzir a ansiedade existencial na pessoa quanto gerar sentimentos de culpa (RIBEIRO, 2011).

A controvérsia exposta pelo autor acima possibilita reflexão de que às vezes o paciente pode se sentir culpado, não merecedor da redenção, podendo essa ser compreendida, no âmbito de libertação da droga, como ato de a pessoa redimir-se, compensando o erro (uso de drogas) mediante ato redentório (participar do culto religioso toda semana ou orar toda noite, por exemplo). Outra questấo envolve a necessidade de compaixão e piedade divinas, principalmente no processo de recaída, o que também pode desencadear na pessoa que usa drogas sentimentos náo só de culpa mas de não ter cumprido um "acordo" divino, o que desencadearia um quadro de ansiedade.

Portanto é necessário que os profissionais de saúde, bem como os teólogos e líderes religiosos, aqui considerados recursos da rede de apoio e suporte social para os usuários de substâncias psicoativas, saibam identificar quais são as características das formas de religiáo que podem promover a saúde mental e quais as que podem ser prejudiciais para o indivíduo (LARANJEIRA et al., 2010; RIBEIRO, 2011).

\section{Conclusão}

A partir da análise dos dados e considerando-se os objetivos propostos neste estudo, a pesquisa evidenciou que a população de uma determinada USF situada em um município do interior paulista apresenta um perfil de padrão de consumo de baixo risco de bebida alcoólica, sendo a maioria do sexo feminino e com predomínio de usuários que buscam atendimento correspondentes à faixa etária produtiva, ou seja, de 20 a 50 anos. Dessa maneira, o acesso do homem à atenção primária à saúde ainda é um fator preocupante, considerando que dados epidemiológicos nacionais sobre o uso prejudicial de álcool apontam um índice maior para a população masculina. Portanto, há necessidade de investir em programas de saúde do homem que incluam tal temática, como também em estratégias facilitadoras de acesso dessa população específica à USF.

Dessa forma, é necessário que os trabalhadores da rede primária de saúde estejam capacitados para acolher os usuários desses serviços. Ressalta-se que nem sempre o indivíduo que faz uso prejudicial de álcool busca a unidade de saúde voluntariamente, mas devido às consequências desse beber. Portanto, uma estratégia eficiente e eficaz consiste na implementação de instrumentos de rastreamento como, por exemplo, o AUDIT, associados à Intervenção Breve. Tais recursos possibilitam identificar o padrão de uso de álcool de uma população e realizar açóes de promoção à saúde, prevenir de agravos e direcionar o usuário para um tratamento precoce.

Compreende-se que é relevante que os gestores e outros trabalhadores de saúde busquem diagnosticar o 
território em que está inserida a USF, apropriando-se de dados epidemiológicos através da utilização de recursos simples e rápidos para planejarem intervençốes eficientes, tanto no âmbito preventivo como no de tratamento.

A atual pesquisa despertou reflexóes sobre a temática de álcool e, mais especificamente, indicou que há possibilidades da inserção de tais instrumentos no âmbito da rotina do trabalho de profissionais de saúde.

Este estudo apresentou limites metodológicos, porém os seus resultados reproduziram dados epidemiológicas muito parecidos com o panorama nacional brasileiro, sendo que tais evidências merecem atenção de autoridades sanitárias locais e de outros setores. O álcool é um tema que ainda desperta e motiva os pesquisadores, mas que apresenta ainda muitos desafios a serem enfrentados.

\section{Referências}

AMATO, T. C. et al. Uso de bebida alcoólica, religiấo e outras características sociodemográficas em pacientes da atenção primária à saúde - Juiz de Fora, MG, Brasil - 2006. SMAD: Revista Eletrônica Saúde Mental Álcool e Drogas, Ribeirão Preto, v. 4, n. 2, p. 1-17, 2008. Disponível em: $<$ http://pepsic.bvsalud.org/pdf/smad/v4n2/v4n2a05. pdf>. Acesso em: 1 jul. 2011.

ABDALA, G. A. et al. A religiosidade/espiritualidade como influência positiva na abstinência, redução e/ou abandono do uso de drogas. Revista Formadores: Vivencias e Estudos, Cachoeira, v. 2, n. 3, p. 447-60, 2009. Disponível em: <http://www.publicacoesfadba.com.br/index.php/ formadores/article/view/32/27>. Acesso em: 1 jul. 2011.

BABOR, T. F. et al. AUDIT: The Alcohol Use Disorders Identification Test. guidelines for use in primary care. 2. ed. Geneva: World Health Organization, 2001. Disponível em: $<$ http://whqlibdoc.who.int/hq/2001/who_msd_msb_01.6a. pdf>. Acesso em: 10 abr. 2010.

BREVIDELLI, M. M.; DOMENICO, E. B. L. Trabalho de conclusão de curso: guia prático para docentes e alunos da área da saúde. São Paulo: Iátria, 2006.

BORDIN, S. et al. Dependência química na mulher. In: FIGLIE, N. B.; BORDIN, S.; LARANJEIRA, R. Aconselhamento em dependência química. Sáo Paulo: Roca, 2010. p. 395-404.

BUSSAB, W. O.; MORETTIM, P. A. Estatística básica. São Paulo: Saraiva, 2004.

CAMPANA, H. C. R. et al. A percepçáo dos mestrandos de enfermagem a respeito da religiấo com recurso terapêutico no processo de recuperação do ser humano doente e sua família. Cogitare Enfermagem, Maringá, v. 13, n. 1, p. 44-51, 2008. Disponível em: <http://ojs.c3sl.ufpr. br/ojs2/index.php/cogitare/article/view/11950/8432>. Acesso em: 17 fev. 2014.
CARLINI, E. A. et al. II Levantamento domiciliar sobre o uso de drogas psicotrópicas no Brasil: estudo envolvendo as 108 maiores cidades do país. São Paulo: CEBRID; UNIFESP, 2006.

DALGALARRONDO, P. et al. Religião e uso de drogas por adolescentes. Revista Brasileira de Psiquiatria, São Paulo, v. 26, n. 2, p. 82-90, 2004. Disponível em: <http:// www.scielo.br/scielo.php?script=sci_arttext\&pid=S1516$44462004000200004 \& \operatorname{lng}=e n \& n r m=i s o>$. Acesso em: 17 fev. 2014

GALDURÓZ, J. C. F.; CAETANO, R. Epidemiologia do uso de álcool no Brasil. Revista Brasileira de Psiquiatria, São Paulo, v. 26, n. 1, p. 3-6, 2004.

GONÇALVES, A. M. S. Estudos dos niveis motivacionais em relação ao uso de substancias psicoativas e a espiritualidade. 2008. 113 f. Dissertação (Mestrado em Enfermagem Psiquiátrica)-Universidade de São Paulo, Ribeirão Preto, 2008.

KOENIG, H. G. Religion and medicine IV: religion, physical health, and clinical implications. International Journal Psychiatry Medical, New York, v. 31, n. 3, p. 321-336, 2001. http://dx.doi.org/10.2190/ X28K-GDAY-75QV-G69N

LARANJEIRA, R. et al. I Levantamento Nacional sobre os padrōes de consumo de álcool na população brasileira. Brasília: Secretaria Nacional Antidrogas, 2007. Disponível em: <http://bvsms.saude.gov.br/bvs/publicacoes/relatorio_ padroes_consumo_alcool.pdf $>$. Acesso em: 10 abr. 2010.

LARANJEIRA, R. et al. Alcohol use patterns among Brazilian adults. Revista Brasileira de Psiquiatria, São Paulo, v. 32, n. 3, p. 231-41, 2010.

MARINHO, J. A. C.; SILVA, I. F.; FERREIRA, S. L. Terapia de rede social e de 12 passos. In: DIEHL, A.; CORDEIRO, D. C.; LARANJEIRA, R. Dependência quimica: prevençấo, tratamento e políticas públicas. Porto Alegre: Artmed, 2011. p. 301-310.

MINTO, E. C. et al. Intervençóes breves para o uso abusivo de álcool em atençáo primária. Revista Epidemiológica de Serviço de Saúde, Brasília, v. 16, n. 3, p. 207-220, 2007.

NOBREGA, M. P. S. S.; OLIVEIRA, L. M. Mulheres usuárias de álcool: análise qualitativa. Revista de Saúde Pública, São Paulo, v. 39, n. 5, p. 823-823, 2005.

PEUKER, A. C.; FOGAÇA, J.; BIZARRO, L. Expectativas e beber problemático entre universitários. Psicologia: Teoria e Pesquisa, São Paulo, v. 22, n. 2, p. 193-200, 2006. http://dx.doi.org/10.1590/S0102-37722006000200009 PILLON, S. C.; CORRADI-WEBSTER, C. M. Teste de identificaçấo de problemas relacionados ao uso de álcool entre estudantes universitários. Revista de Enfermagem da UERJ, Brasília, v. 14, n. 3, p. 325-332, 2006.

RIBEIRO, H. L. M. Espiritualidade e dependência química. In: DIEHL, A.; CORDEIRO, D. C.; LARANJEIRA, R. Dependência quimica: prevenção, tratamento e políticas públicas. Porto Alegre: Artmed, 2011. p. 177-184. PMid:21214389. 
ROEHE, M. V. Experiência religiosa em grupos de auto-ajuda: o exemplo de neuróticos anônimos. Revista de Psicologia em Estudo, Maringá, v. 9, n. 3, p. 399-407, 2004.

RONZANI, T. M.; FORMIGONI, M. L. O. S.; MAGNABOSCO, M. B. Avaliação dos padrôes de uso de álcool em usuários de serviços de Atenção Primária à Saúde de Juiz de Fora e Rio Pomba (MG). Revista Brasileira de Epidemiologia, São Paulo, v. 10, n. 4, p. 637-47, 2007. http://dx.doi.org/10.1590/S1415-790X2007000400021 SILVA, M. E. D. C. et al. Resistência dos homens às açôes de saúde:percepção de enfermeiras da Estratégia
Saúde da família. Revista Interdisciplinar NOVAFAPI, Teresina, v. 3, n. 3, p. 21-5, 2010.

VARGAS, D.; OLIVEIRA, M. A. F.; ARAÚJO, E. C. Prevalência de dependência alcoólica em serviços de atenção primária à saúde de Bebedouro, São Paulo, Brasil. Cadernos de Saúde Pública, Rio de Janeiro, v. 25, n. 8, p. 1711-20, 2008.

WOLLE, C. C.; ZILBERMAN, M. L. In: DIEHL, A.; CORDEIRO, D. C.; LARANJEIRA, R. (Org.). Dependência química: prevenção, tratamento e políticas públicas. Porto Alegre: Artmed, 2011. p. 375-382.

\section{Contribuição de Autores}

Renata Gomes Sanches Verardino contribuiu substancialmente para a concepção, planejamento, análise, interpretação dos dados e redação do manuscrito. Sonia Regina Zerbetto contribuiu na concepção, planejamento, análise e interpretação dos dados, revisão crítica do conteúdo e na aprovaçáo da versão final do manuscrito.

\section{Notas}

${ }^{1}$ Artigo derivado do Programa Institucional de Bolsas de Iniciação Científica (PIBIC), com apoio do Conselho Nacional de Desenvolvimento Científico e Tecnológico (CNPq), aprovado pelo Comitê de Ética em Pesquisa em Seres Humanos da Universidade Federal de Sáo Carlos - UFSCar conforme o parecer n. 286/2011 e apresentado em congresso e publicado em forma de resumo em anais.

${ }^{2}$ Intervençốes Breves constituem ações de curta duração com objetivo de identificar um problema com o álcool e motivar a pessoa a decidir-se pela reduçáo do consumo de bebida alcoólica ou abstemia (MINTO et al., 2007). 